\title{
Sanjaju li androidi električne ovce? kao simulacija detektivskog romana
}

Mirko Ž. Šešlak*

Univerzitet u Beogradu, Filološki fakultet

Ključne reči:
detektivska književnost
naučna fantastika
Filip K. Dik
Darko Suvin
androidi
androidizacija

\begin{abstract}
Apstrakt
Posmatrajući roman Sanjaju li androidi električne ovce? iz ugla teorije mogućih svetova prema Lubomiru Doleželu i teorijskih razmatranja Darka Suvina o naučnoj fantastici, ovaj rad analizira način na koji pisac prilagođava zaplet karakterističan za detektivsku književnost, epistemičku pripovest priče sa tajnom (mystery story) u unutrašnju potragu glavnog junaka naučnofantastične pripovesti za transformacijom neznanja o sebi u samospoznaju. Nasuprot dvodimenzionalnim likovima klasične detektivske pripovesti, Dikovi likovi su višeslojni i njihove motivacije nije lako dokučiti. Na taj način, Dik čitaocu uskraćuje klasično eskapističko razrešenje detektivske književnosti koje za cilj ima otpuštanje napetosti i odmor od realnosti. Dik čitaoca prisiljava da se sa realnošću suoči umesto da od nje beži. Gotovo sva njegova dela primoravaju čitaoca da se na svet u kome živi osvrne sa podozrenjem. Težnja ka spoznaji stvarnosti svrha je takvog književnog dela. (примљено: 12. маја 2021; прихваћено: 15. септембра 2021)
\end{abstract}




\section{Uvod}

Ukoliko zamolimo čitaoca da nam da mišljenje kome žanru pripisati roman Filipa Kindreda Dika (Philip Kindred Dick), Sanjaju li androidi električne ovce?, odgovor koji bismo verovatno dobili jeste da pripada naučnoj fantastici. Ukoliko bismo ispitivanje nastavili na većem uzorku čitalaca, odgovor se ne bi mnogo promenio, možda bi tek poneko primetio da u tom romanu postoje i elementi detektivske književnosti. Naravno, veoma je problematično šta bi ispitanici podrazumevali pod pojmovima bilo detektivske književnosti, bilo naučne fantastike. Iz tog razloga, neophodno je razgraničiti pojmove i odrediti na šta se misli kada se govori o detektivskoj, a na šta kada se govori o naučnofantastičnoj književnosti.

Teza je našeg rada da do zamagljivanja žanrovskih granica dolazi i u naučnofantastičnom romanu Sanjaju li androidi električne ovce? Dik prilagođava zaplet detektivske književnosti, epistemičku pripovest priče sa tajnom (mystery story) u potragu glavnog junaka. U knjizi Heterokosmika: Fikcija i mogući svetovi ${ }^{1}$, Lubomir Doležel (Lubomír Doležel) ističe kako je priča sa tajnom „poseban [...] slučaj epistemičke potrage, pripovesti čija je modalna osnova transformacija neznanja ili pogrešnog uverenja u znanje“ (2008: 137). Zamenom klasičnog obrasca „saspens-iznenađenje“ (Doležel, 2008: 137), Sanjaju li androidi električne ovce? postaje priča ne o detektivu koji rešava zagonetku, već o epistemičkoj potrazi čija se struktura „nalazi i u srži obrazovnog romana“ (Doležel, 2008: 137). Potraga lovca na glave androida postaje istovremeno i unutrašnja potraga za „transformacij[om] neznanja (nepoznavanja sebe) u znanje (samospoznaju)“ (Doležel, 2008: 137). Lovac na glave, Rik Dekard, donekle se uklapa u klasični opis detektiva kao neko ko je „čudak“, „neobičan [...] po ponašanju“ i „egzistencijalni osobenjak“ (Šarkanj, 2017: 23). Ipak, Dik problematizuje zaplet koji se razvija oko takvog aktera tako što razbija njegov redosled, zločinistraga-razrešenje, budući da Dekard zna koga treba odstreliti. Još snažniji efekat Dik postiže oslikavanjem fikcionalnog sveta romana ne kao jednostavnog, već i doslovno sivog, gde crno i belo postaje nerazaznatljivo. Dobro i zlo postaju isprepleteni i stopljeni u gotovo istu ravan. Dekardovi postupci sa jedne, te postupci progonjenih androida sa druge strane, ne mogu se posmatrati kroz prizmu binarnih opozicija karakterističnih za detektivsku književnost zlatnog doba. U studiji „Zlatno doba“ ("The Golden Age")", Stiven Najt (Stephen Knight) uočava jednu od značajnih odlika zlatnog doba detektivske književnosti: „Čak i kada bi lik detektiva bio detaljnije opisan, težio bi dvodimenzionalnosti“ (Knight, 2003: 78). Nasuprot tome, Dikovi likovi su višeslojni i njihove motivacije (poput motivacija ljudi naše stvarnosti) nije lako dokučiti. Na taj način, Dik čitaocu uskraćuje eskapističko razrešenje detektivske književnosti koje za cilj ima otpuštanje psihološke napetosti i odmor od realnosti.

1 Knjiga je prvi put objavljena na engleskom jeziku 1998. godine pod naslovom Heterocosmica: Fiction and Possible Worlds. Prevod koji koristimo objavljen je 2008. godine.

2 Studija je prvi put objavljena u Kembridžovom vodiču u kriminalističku književnost urednika Martina Pristmana 2003. godine. Nije prevedena na srpski jezik. Sve navode pomenutog izvora preveo je autor rada. 


\section{Detektivska književnost ili naučna fantastika?}

Prema Najtu (Knight, 2003: 78-79), osnovna tema detektivske književnosti zlatnog doba jeste zločin i potraga za počiniocem. Lik koji za zločincem traga čini to na racionalan način. Ta osoba obično je „bilo amater, bilo [...] predstavnik policije koji se izdvaja (obično po pripadnosti klasi) od tipičnog policajca“ (Knight, 2003: 78). Detektiv je najčešće predstavljen dvodimenzionalno. Hapšenje počinioca „najčešće [je] predstavljeno bez melodrame: kao i kod smrti žrtve, ton [pripovesti] je razuman i sveden“ (Knight, 2003: 79). Takvu formu detektivske priče, „zagonetk[u] sa tragovima“3 (Knight, 2003: 79), Najt opisuje kao eskapističku, ali istovremeno kompleksnu, jer „kombinuje utehu sa strepnjom“ (Knight, 2003: 91), usled toga što „gradi prostor u kome čitalac može deliti autorovu inteligenciju i sveznanje“ (Knight, 2003: 90). Za razliku od čitaočeve stvarnosti, u tom svetu ne postoje problemi koji se ne mogu rešiti snagom racionalnog uma.

U uvodu za Kembridžov vodič u kriminalističku književnost (The Cambridge Companion to Crime Fiction) ${ }^{4}$, Martin Pristman (Martin Priestman) ističe da ta vrsta književnosti počinje pričama Edgara Alana Poa sredinom XIX veka, razvija se u delima Artura Konana Dojla potkraj istog, te ulazi u tzv. „zlatno doba“ posle Prvog svetskog rata, u kome se izdvaja Agata Kristi (Priestman, 2003a: 1-6). Kao odgovor na „engleski model“ zlatnog doba, u SAD se razvija „tvrda fikcija privatnog detektiva“" (Priestman, 2003a: 2). Na osnovu izloženog, jasno je da takva književnost pruža pojednostavljenu sliku fikcionalnog sveta, gde čitalac u svakom trenutku zna sa kim se može poistovetiti. Očigledna je privlačnost takve književnosti kao vida eskapizma. Za razliku od naše empirijske realnosti, motivacije likova lako se razlučuju kao dobre ili zle. Pozivajući se na Pristmana, Martin A. Kejman (Martin A. Kayman) u studiji „Kratka priča od Poa do Čestertona“ ("The Short Story from Poe to Chesterton”) $)^{5}$ skreće pažnju na strukturu Dojlovih priča o Šerloku Holmsu kao „reprodukovanoj u epistemologiji samih priča, u kojoj se [...] svi pojedinačni fragmenti i događaji na koncu pokazuju povezanima u koherentnom linearnom nizu stvarajući smislenu i umirujuću sliku društvenog poretka“ (Kayman, 2003: 43). Suzan Rouland (Susan Rowland) u studiji „Klasični' model Zlatnog doba“ (“The 'Classical' Model of the Golden Age” ${ }^{6}$, ističe kako ta književna vrsta obezbeđuje „visok stepen učešća čitaoca u atmosferi bezbednosti“, jer „nudi priče koje čitaoca potpuno obuzimaju, a da ga nikada istinski ne izazovu“ (Rowland, 2010: 117). Slikovito rečeno, sve je crno ili belo, zasnovano na poznatim binarnim opozicijama Nas naspram Njih, dobrog naspram zlog. Za razliku od empirijske realnosti, nerešivih slučajeva gotovo da i nema. Takve okolnosti pružaju čitaocu razrešenje i otpuštanje napetosti. U magi-

3 Eng "clue-puzzle"

4 Knjiga je prvi put štampana na engleskom jeziku 2003. godine. Nije prevedena na srpski jezik. Sve navode pomenutog izvora preveo je autor rada.

5 Studija je prvi put objavljena u Kembridžovom vodiču u kriminalističku književnost urednika Martina Pristmana 2003. godine. Nije prevedena na srpski jezik. Sve navode pomenutog izvora preveo je autor rada.

6 Studija je prvi put objavljena na engleskom jeziku u Vodiču u kriminalističku književnost (A Companion to Crime Fiction) urednika Čarlsa Ržepke (Charles J. Rzepka) i Lija Horslija (Lee Horsley) 2010. godine. Nije prevedena na srpski jezik. Sve navode pomenutog izvora preveo je autor rada. 
starskom radu Suvremeni kriminalistički roman na primjerima Gorana Tribusona, Pavla Pavličića i Milorada Stojevića (2017), Danijela Šarkanj o tome govori kao o optimizmu kriminalističkog romana: „[U]bojica je uvijek na kraju uhvaćen, pravda je izvršena, a ravnoteža uspostavljena“ (2017: 21). Pomenuta odlika tu književnu vrstu čini privlačnom industriji zabave, čemu svedoče hiljade snimljenih filmova i televizijskih serija.

U periodu nakon Drugog svetskog rata, kriminalistička fikcija počela je usvajati elemente drugih književnih vrsta. O tome govori Liroj L. Panek (Leroy L. Panek) u studiji „Posleratna američka policijska fikcija“ (“Post-war American Police Fiction”)":

[O]d kasnih 1960-ih policijski roman počeo je da se javlja u različitim oblicima, od klasičnog, preko trilera, do ljubavne romanse. Bez obzira na pripovednu strukturu, svi ti oblici fokusirali su se na istu tvrdnju - da kriminalistički i policijski posao imaju osoben uticaj na kako način rada, tako i način života muškaraca i žena koji se njim bave. (Panek, 2003: 156)

Ukoliko su elementi drugih vrsta fikcije mogli postati delom kriminalističke književnosti, logično je zaključiti da je isto tačno i u obrnutom smeru. Takav stav zastupa Uroš Tomić u doktorskoj disertaciji Britanski kriminalistički roman - ključni aspekti razvoja (2013). Tomić govori o problemu definisanja granica žanra u savremenoj književnosti, budući da se neretko „pod odrednicu jednog žanra svrstava skoro beskonačan broj varijacija apstraktne žanrovske formule“ (2013: 1). Usled takvih kretanja, „1980-ih i 1990-ih policijski roman postao [je] mnogo fleksibilnija forma - koja je mogla koristiti stare tragove i obrasce iznenađenja formalne detektivske priče, ali koja je takođe mogla da uposli tehnike psihološkog romana ili trilera" (Panek, 2003: 158-160). Sličnu pojavu primećuje i Pristman u studiji „Posleratna britanska kriminalistička fikcija“ (“Post-war British Crime Fiction”) ${ }^{8}$ „ „Nekada istaknuta formula zločina, lažnih tragova i trijumfalnog rešenja briljantnog detektiva izgledala je bilo zastarela, bilo zamenjena drugim izvorima interesovanja, poput špijunaže ili psihološke neizvesnosti“ (Priestman, 2003b: 173). Problematizovanje tih granica reakcija je na klasični zaplet detektivske književnosti i njegovo konstruisanje fikcionalne realnosti kao jednostavnog sveta binarnih opozicija dobrog naspram zlog. U postmodernom kriminalističkom romanu, više ni „[p]risustvo detektiva nije neophodno“, a često „nije neophodno ponuditi ni razrešenje misterije“ (Tomić, 2013: 1). Samim tim, pokušaj precizne žanrovske klasifikacije u savremenoj književnosti postaje uslovni: „[N]eminovno vodi u paradokse i često nužno provizorne odrednice u naporu da se uvede barem privid reda u jedno žanrovsko književno polje“ (Tomić, 2013: 1).

Kako ističe Mladen Jakovljević u knjizi Alternativne stvarnosti Filipa K. Dika (2015), Dik čitaoca prisiljava da se sa realnošću suoči. Gotovo sva njegova dela „svo-

7 Studija je prvi put objavljena u Kembridžovom vodiču u kriminalističku književnost urednika Martina Pristmana 2003. godine. Nije prevedena na srpski jezik. Sve navode pomenutog izvora preveo je autor rada.

8 Studija je prvi put objavljena u Kembridžovom vodiču u kriminalističku književnost urednika Martina Pristmana 2003. godine. Nije prevedena na srpski jezik. Sve navode pomenutog izvora preveo je autor rada. 
jom neodoljivom zavodljivošću inspirišu čitaoca da se osvrne i svet u kojem živi osmotri s podozrenjem“ (2015: 7). Dik koristi elemente zapleta detektivske književnosti u svrhe suprotne onima klasične detektivske priče. Težnja ka spoznaji realnosti čitaoca, te podsticanje spoznaje transpozicijom fikcionalne radnje u drugo prostor-vreme, dovodi do toga da se, analogijom, empirijska realnost sagledava iz novog ugla. U svojim teorijskim radovima o naučnoj fantastici, Darko Suvin takav postupak naziva kognitivno očuđenje ${ }^{9}$. Njegovo prisustvo u fikcionalnom delu svrstava ga u književnu vrstu naučne fantastike, bez obzira na prisustvo drugih elemenata. Nasuprot tome, Žan Bodrijar (Jean Baudrillard) u delu Simulakrumi i simulacija ${ }^{10}$ ne klasifikuje Dikova dela kao naučnu fantastiku. Povezujući ih sa trećom vrstom simulakruma (simulakrumi simulacije), o kojima piše razmatrajući perspektive naučne fantastike, Bodrijar ističe kako je „dobri stari imaginarni svet naučne fantastike mrtav i da se nešto drugo upravo pojavljuje“ (1991: 122). U eri simulacija i gubljenja reference prema stvarnom „[n]ije više moguće poći od stvarnog i proizvoditi nestvarno, imaginarno, na osnovu datosti stvarnog“ (1991: 125). Dikova dela gravitiraju novom prostoru koji prevazilazi naučnu fantastiku, budući da „ne predočavaju neki alternativni kosmos [...] nego nas smesta uvode u totalnu simulaciju, bez porekla, imanentnu [...] u njima nije reč o nekom paralelnom univerzumu [...] ili čak o nekom mogućem svetu - ni mogućem, ni nemogućem, ni stvarnom, nego nadstvarnom; to je svet simulacije, što je sasvim druga stvar“ (1991: 126). Dikova dela su nadstvarna, jer ne govore o fikcionalnom svetu koji referira na empirijsku stvarnost, već o simulaciji koja referira na simulaciju koju živimo. Suvin se sa takvim stavovima ne bi složio, prvenstveno usled Bodrijarovog insistiranja na ekstrapolaciji kao definišućoj odlici naučnofantastične književnosti. Suvin tu odliku smatra sekundarnom, simulacijom ekstrapolacije. Bodrijarovo karakterisanje naučne fantastike kao nestvarne suprotno je smeru Suvinovih razmatranja, budući da je Suvin posmatra kao analoški utemeljenu u empirijskoj realnosti.

U pokušaju da obrazloži funkcije naučne fantastike, te odredi njen opseg između mogućih fikcionalnih svetova realističke književnosti, sa jedne strane, i natprirodnih fikcionalnih svetova fantastike, bajki i mitova sa druge, Suvin nudi definiciju naučne fantastike kao „književne vrste zasnovane na prožimanju začudnosti i spoznajnosti, čiji je glavni formalni zahvat eksplicitni imaginativni okvir [...] koji je alternativan autorovoj empirijskoj svakidašnjici“ (2009: 41). Razliku između naučnofantastične i fantastične književnosti Suvin obrazlaže na sličan način kao i Doležel (2008: 24). Iz ugla teorije mogućih svetova, naučna fantastika pripada modelativnom okviru prirodnih mogućih svetova, neguje saznajnu funkciju književnosti. Fantastična književnost deo je modelativnog okvira natprirodnih mogućih svetova. Takva dela ne poseduju saznajnu vrednost, tj. čitaocu ne govore ništa o stvarnosti koju živi. Suvin kritikuje i zabludu da je naučna fantastika futurološka književna vrsta koja se bavi predviđanjima. Svet takvog dela ne modelira se ekstrapolacijom,

9 Eng. „cognitive estrangement"

10 Knjiga je prvi put objavljena na francuskom jeziku 1981. godine, pod naslovom Simulacres et Simulation. Prevod koji koristimo objavljen je 1991. godine. 
već analogijom. Iz tog razloga, „njegovi likovi ne moraju biti čovjekoliki niti lokalitet geomorfan (sličan Zemlji)“, dok realije modelovanog sveta, „mogu biti veoma 'fantastične', pod uslovom da nisu logičko-filozofski nemoguće ili međusobno proturječne“ (Suvin, 2009: 45). Predstavljeni odnosi u naučnofantastičnom delu „uvijek govore o autorovoj sadašnjosti, što god bilo navodno prostorvrijeme odabrano za pripovijedanje te njegova prijatna ili nakazna amorfna izobličenja [...] dakle, oni govore na zaobilazni način parabole“ (Suvin, 2009: 299). U temeljima takvog modela nalazi se naučnofantastični novum kao differentia specifica naučne fantastike (Suvin, 2009: 72). Suvin definiše novum kao spoznajnu inovaciju, totalizirajuću pojavu ili odnos „koji odstupa od piščeve - i pretpostavljene čitaočeve - stvarnosne norme“ (Suvin, 2009: 72-73). Takva novina postoji i u fantastičnoj književnosti, s tom razlikom što „[u] pravoj nadnaravnoj fantastici pretpostavljena novina odbacuje spoznajnu logiku i ističe pravo na višu 'okultnu' logiku“ (Suvin, 2009: 77). Nasuprot tome, „nemoguće [je] da SF prizna bilo kakvu metafizičku silu, u doslovnom smislu sile koja prelazi granice physisa (prirode)“ (Suvin, 2009: 75). Preuzimajući pojam očuđenja (ostranenie) od ruskih formalista, Suvin kognitivno očuđenje definiše kao povratnu spregu „koja se sada vraća od norme pisca i pretpostavljenog čitaoca $\mathrm{k}$ pripovijedanjem ostvarenom novumu da bi se mogli razumjeti elementi zapleta, a sada ponovo natrag, od tih novosti $\mathrm{k}$ piščevoj stvarnosti, da bi se ona mogla sagledati iznova, iz svježe perspektive“ (2009: 80). Realije naučne fantastike poput vanzemaljaca, robota ili androida označavaju isključivo ljudske odnose, „budući da druge [...] ne možemo zamisliti“ (Suvin, 2009: 80). Povratna sprega, kroz proces kognitivnog očuđenja, deluje na čitaočevo shvatanje sopstvenih iskustvenih normi, omogućavajući mu da ih kritički preispita. To se može pokazati na primeru romana Sanjaju li androidi električne ovce? Novum postojanja androida i transpozicija zapleta detektivske priče u postapokaliptični svet budućnosti, analogija su na čitaočevu iskustvenu stvarnost. Popularnost Dikove proze leži u temama kojima se bavi, a koje čitalac prepoznaje u svetu oko sebe. Tu i leži njihova spoznajna vrednost:

To su priče o industrijskom društvu i tržišno orijentisanoj ekonomiji, kao i o postindustrijskom društvu, u kome se proizvode i konzumiraju koncepti i informacije. U sumornoj svakodnevici njegovih fikcionalnih stvarnosti sve može postati utrživa roba koju je moguće proizvesti i prodati, od klasičnih potrošačkih proizvoda, preko replika predmeta, životinja i ljudi, pa sve do prošlosti, sećanja i same stvarnosti. (Jakovljević, 2015: 84)

Spoznaja u Sanjaju li androidi električne ovce? nije ograničena na čitaoca. Do nje dolaze i junaci pripovesti. Tipični rasplet detektivske književnosti zamenjen je psihološkom spoznajom koja iz korena menja doživljaj sveta glavnih junaka. Motiv psihološkog putovanja Dik koristi kako bi postigao efekat suprotan onom klasičnog detektivskog romana. Ne postoji razrešenje u kome je pravda zadovoljena. Čak i značenje pojma pravičnosti dovedeno je u pitanje. Akteri ne bivaju izmireni sa svojim svetom. Naprotiv, na njega gledaju sa rastućim podozrenjem. Svrha spoznaje više nije njihovo prilagođavanje svetu, već razaranje iluzija koje su o svetu imali. 


\section{Sanjaju li androidi električne ovce?}

Jedna od glavnih tema kojima se Sanjaju li androidi električne ovce? bavi jeste pitanje šta nas čini ljudima i razlikuje od simulacija čoveka. Naslov romana je dvosmislen. Pripisuje sposobnost snivanja nečemu što se ne smatra živim i (navodno) nema svest, androidima. To porađa dilemu: ako androidi nisu svesni, nisu sposobni da sanjaju; međutim, ukoliko su sposobni da imaju snove, to znači da nisu neživi predmeti, što iz korena menja našu koncepciju stvarnosti:

Nepostojanje spoljašnjih i fizioloških razlika između ljudi i replika u ovom romanu pak doprinosi njihovom zastrašujućem potencijalu da izbrišu sve razlike između autentičnog čoveka i mašine, jer spoljašnja sličnost ima ogroman značaj u vizualno orijentisanoj i medijskoj kulturi i okruženju kakvo je savremeno potrošačko društvo. (Jakovljević, 2015: 96-97)

Pripovest romana svojim naslovom ukazuje na „problematiku postojanja mehaničkog života i svesti mašina“ (Jakovljević, 2011: 232). O snovima kao odlikama ljudske svesti Jakovljević dodaje: „Osim uznemirujuće pomisli da androidi imaju snove, svest i podsvest, naslov ukazuje i da android, kao lažni čovek, koji sanja električne ovce, još jednu lažnu stvar, stvara lažnu stvarnost, koja je bodrijarovska, totalna simulacija“ (2011: 232).

Da li androidi mogu da se nazovu živim bićima pitanje je koje se provlači kroz mnoga dela, ne samo naučne fantastike. Budući da je deo šire percepcije realnosti, javlja se i u filozofskim, sociološkim i antropološkim raspravama. U prvom poglavlju zbornika radova Svi naši svetovi. O antropologiji, naučnoj fantastici i fantaziji (2011), „Antropologija izmišljenih svetova“, Ljiljana Gavrilović kaže:

Postmoderne društvene nauke, ne samo antropologija, nego i istorija, sociologija, kulturne studije, ali i neke prirodne nauke, kao što je geografija, shvatile su, [...] da je sve ono što se do poslednje četvrtine 20. veka smatralo objektivnim istinama, u velikoj meri stvar percepcije i diskursa, da se posmatrano stvarno ponovo oblikuje pod uticajem posmatrača. Zbog toga se posmatranje izmišljenih svetova nimalo ne razlikuje od posmatranja 'stvarnog' sveta, onog u kome živimo. Oni, možda čak i jasnije, odražavaju sva uverenja, strahove, nade, snove, konstrukcije i predubeđenja koja oblikuju ponašanje ljudi u stvarnom svetu, njihovo viđenje tog sveta, pa tako $i$ sam taj svet. (Gavrilović, 2011: 8)

O postojanju svesti raspravlja se i kroz Kantovu filozofiju. Lovro Grgić, u članku Šta ako androidi zaista sanjaju električne ovce? (2009), ističući Dikove androide kao živa i moralna bića, pravi razliku između uma i inteligencije, pozivajući se na Kantovu Kritiku praktičnog uma:

Problem je jedino može li se pokazati da androidi posjeduju um i volju. Prethodno je rečeno da posjeduju inteligenciju (Dick dodaje i sklonost $k$ apstrak- 
tnom mišljenju), a za Kanta je to dostatno: 'Biće pak, koje je sposobno za djelovanje prema predodžbi, jest inteligencija (umno biće), a kauzalitet je takvog bića prema toj predodžbi zakona njegova volja.' (Kant 1974: 173) Prema tome, Dickov android je, unatoč tomu što je umjetno stvoren putem znanošću omogućene tehnike, moralno biće par excellence. (Grgić, 2009: 75)

Radnja romana Sanjaju li androidi električne ovce? odigrava se u postapokaliptičnoj budućnosti ${ }^{11}$, na Zemlji prekrivenoj radioaktivnom prašinom. U prilagođenom zapletu detektivskog romana, pratimo lovca na glave, Rika Dekarda, na zadatku da eliminiše šest androida koji su pobegli na Zemlju sa kolonizovanog Marsa, gde se koriste kao robovska radna snaga. Navodno su toliko slični ljudima da ih od nas razlikuje jedino nedostatak empatije. U tom svetu „[s]vi nivoi stvarnosti su izloženi dejstvu entropije, koja, osim propadanja stvari i biološkog materijala, uzrokuje i eroziju emotivnih sposobnosti i kapaciteta ličnosti, što čoveka još više udaljava od autentične stvarnosti i iskustva“ (Jakovljević, 2015: 101). To je svet privida i paradoksa, u kome ljudi pomoću aparata (Tvorac raspoloženja) programiraju osećanja, iako se njima diče kao potvrdom svoje ljudskosti. To je svet u kome je dominantna religija Mercerizam, pseudo-religija u kojoj se pomoću empat-kutije korisnik sjedinjuje sa Mercerom, dok on biva zasipan kamenicama: „Ovo je još jedan primer inverznog paralelizma u romanu - programiranjem emocija ljudi postaju automatizovani, dok androidi teže emocijama koje će biti što sličnije ljudskim“ (Jakovljević, 2015: 97). Empat-kutija samo je jedna u nizu simulacija, iskustvo koje „nalikuje ulasku u virtualnu stvarnost u kojoj korisnik doživljava iskustva Vilbura Mercera“ (Jakovljević, 2015: 101). Pritom, Mercer je laž. Osoba za koju svi veruju da je Mercer nepoznati je glumac. Ipak, Mercerizam kao religija ne nestaje nakon takvog otkrića. Preživljava kao što su i mnoge druge religije preživele neprijatna otkrovenja. Sa jedne strane, takve okolnosti oslikavaju ljudsku potrebu za pripadnošću nečemu većem od sebe. Sa druge strane, oslikavaju ljudsku nesposobnost za suočavanje sa istinom, sklonost ka begu u samoobmane pred stvarnim problemima. Mercerizam je zapravo „sopstveni simulakrum, simulacij[a] bez originala i porekla, koje grad[i] novu, sopstvenu stvarnost" (Jakovljević, 2015: 109).

U svakodnevnom značenju, empatija je sposobnost da sebi predstavimo osećanja drugih, te da se shodno tome prema njima i postavimo. Nasuprot tome, stoji dispatija, kojom Katrin Miselhorn u članku „Empatija i dispatija kod androida“ ("Empathy and Dyspathy with Androids") opisuje ne samo nedostatak empatije, već i krajnju nelagodu (Misselhorn 2009). Dikovi androidi izazivaju dispatiju kod ljudi uprkos tome što su im identični, za razliku od Frankenštajnovog stvorenja u romanu Meri Šeli, koje nalikuje čoveku, ali je neprijatne spoljašnjosti. Jakovljević govori o tome koristeći Frojdov koncept unheimlich:

11 U prvim izdanjima, radnja romana odigravala se 1992. godine. Nakon filma Blade Runner iz 1982. godine, fikcionalni datum pomeren je na 2019. godinu. Naravno, budući da je u pitanju fikcionalni svet koji je analogija na piščevu i čitaočevu iskustvenu stvarnost, a ne puka ekstrapolacija, tačna godina radnje krajnje je nebitna. 
Susret $\mathrm{s}$ androidom je susret $\mathrm{s}$ čudesnim i jezovitim, $\mathrm{s}$ onim što je Frojd definisao kao unheimlich. [...] Odbegli android je heimlich koji postaje unheimlich, slika ljudskog bića koje se pretvara u neljudsko, poput gotske transformacije čoveka u zver ili čudovište. Android, kao verna replika čoveka, njegov je dvojnik [...]. Čovek poistovećen i izjednačen s mašinom, koja je postala unheimlich i sam postaje unheimlich, jer se kao biće bez empatije pretvara u nešto strašno. Android, neautentično koje simulira autentično, koje se infiltrira na mesto čoveka kao njegov savršeni dvojnik, izaziva strah od smrti. (Jakovljević, 2015: 104)

Ukoliko je androida nemoguće razlikovati od čoveka, „kad je neki predmet potpuno sličan drugome on to nije potpuno, on je to malo više" (Bodrijar, 1991: 110), a njegova interakcija s ljudima nije dostigla ravan savršene simulacije, posledica toga jeste osećaj izrazite nelagode. Ponašanje Dikovih androida očigledan je primer. Njihov spoljašnji realizam u neskladu je sa njihovim neprirodnim ponašanjem. To je smišljena posledica njihovog ograničenog veka. Oni funkcionišu samo četiri godine, a forme ponašanja stiču se socijalizacijom za koju je potrebno vreme. Pri susretu sa androidom Pris Straton, jedan od aktera romana, Džon Isidor, nudi joj pomoć u opremanju stana. Zauzvrat, predlaže da ona spremi večeru. Takvo ophođenje uobičajeno je u ljudskom društvu. Njeno neočekivano odbijanje ostavlja Isidora zbunjenim:

Devojka je njegov zahtev odbila bez ikakvog napora, a on je to primetio, ali ne i shvatio. Sad kad je njen početni strah popustio, nešto drugo je počelo da zrači iz nje. Nešto čudnije. Nešto, pomisli on, dostojno osude. Hladnoća. Kao, pomisli on, dah iz onog vakuma nenastanjenih svetova, zapravo dah iz ničega, iz ništavila: nije stvar bila u tome šta ona čini ili govori, nego u onome šta propušta da učini ili kaže. (Dik, 2007: 59-60)

Ukoliko android isuviše nalikuje čoveku, prema takvom stvorenju ljudi će imati očekivanja koja ono neće moći da ispuni. Podatak da „Dick čini svoje robote izrazito antropomorfnima“ (Grgić, 2009: 73) naglašava njihove bodrijarovske karakteristike simulacije: „Ono što je tačno već je suviše tačno“ (Bodrijar, 1991: 110).

Sem straha i nelagode, postoji još jedan razlog zašto ljudi odbacuju androide. Binarnom opozicijom Nas naspram Njih, koja se mnogo puta koristila kako bi se skupina ljudi dehumanizovala po osnovu rasne, verske, etničke, rodne, seksualne ili druge pripadnosti, androidi postaju Drugi i potlačeni. Takav je humanoidni robot „upotrebljen kao tovarna životinja za najteže poslove u okviru programa kolonizacije“" (Dik, 2007: 18). Svaki kolonista dobija androida kao slugu. Reklamom na televizijskom programu androidi se porede sa robovima na nekadašnjem jugu SAD. Oživljavaju „blažene dane južnjačkih država pre građanskog rata ili kao lična posluga ili kao neumorni radnik u polju, humanoidni robot, rađen po meri, konstruisan baš za VAŠE JEDINSTVENE POTREBE“ (Dik, 2007: 19). Isti navod koristi i Ljiljana Gavrilović u studiji „O robotima i ljudima ili: Imaju li roboti dušu?“ (2010). Na taj način, Dik „eksplicitno objašnjava odnos koji se uspostavlja između ljudi i robota“ 
(2010: 102). Aludirajući na istorijski trenutak pisanja romana ${ }^{12}$, „Dik insistira na činjenici da sto godina posle oslobođenja robova u Sjedinjenim Američkim Državama [...] i dalje postoji viđenje perioda ropstva kao 'blaženih dana' (iako se nikada ne kaže za koga su oni bili blaženi, kontekst je jasan)“ (2010: 102).

Usled zagađenja, životinje su u tom fikcionalnom svetu postale retke pa ljudi žele da ih poseduju kao statusni simbol i dokaz svoje sposobnosti da saosećaju sa njima. Ukoliko nemaju novca, kupuju električne životinje kako bi nedostatak pri$\mathrm{krili}^{13}$. Na taj način, empatija postaje utrživa kategorija. Nasuprot tome, androidi se smatraju manje vrednim čak i od električnih životinja: „Rizikujemo u svakom slučaju, već i time što se otkidamo iz ropstva i dolazimo ovde na Zemlju, gde nas ne cene čak ni koliko životinje. Gde se za svaku vaš ili crva smatra da su poželjniji nego svi mi skupa“" (Dik, 2007: 103).

Uprkos svemu, likovima kao što su Dekard i Isidor razlike između ljudi i androida nisu tako jasne. Androidi neretko pokazuju ljudske osobine: težnju za slobodom, sposobnost rasuđivanja, osećanja poput ljubavi, besa, straha. Nasuprot tome, ljudi se često ponašaju hladno i bezosećajno. Kako bi uspeo da razluči čoveka od androida, Dekard koristi test zasnovan na brzini širenja kapilara oka na pitanja o zloupotrebi životinja. Očekuje se refleksna reakcija. Ukoliko nije odgovarajuća, zaključak je da je ispitanik android. Iz perspektive čitaoca, takva pitanja smišljeno naglašavaju problematičnost korišćenja empatije u tu svrhu. Pojedini ljudski likovi, poput lovca na glave Fila Reša, mogu proći test iako nisu kadri da saosećaju. Reš je dobar primer procesa koji Dik naziva androidizacijom, a Jakovljević objašnjava kao čovekovo poistovećivanje sa mašinom. Empatija kao standard dovodi se u pitanje i time što se ljudi oslanjaju na Tvorce raspoloženja, mašine kojima programiraju osećanja. Nasuprot njima, androidi izražavaju naizgled stvarne emocije. Sâm Dekard ističe kako je većina androida koje je upoznao „imala više vitalnosti i želje za životom“ od njegove supruge (Dik, 2007: 81). Za razliku od neosetljivosti ljudskih likova, u trenutku uklanjanja Irmgard Bejti, Roj Bejti ispušta „krik jada“, a Dekard odgovara: „U redu, voleo si je“ (Dik, 2007: 181). Prividna sposobnost za prava osećanja vidna je i u Prisinom opisu života na Marsu: „'Ovo' - ona širokim i silovitim zamahom ruke pokaza kuhinju i čitav stan - 'ovo nije ništa. Mislite da patim što sam usamljena. Vraga, tek na Marsu je usamljeno. Tamo je mnogo gora usamljenost nego ovde.' [...] 'Androidi su', reče ona, 'takođe usamljeni'“ (Dik, 2007: 124).

Androidi su predstavljeni kao donekle humanizovani, jer imaju spontane emocije. Ljudi su neretko dehumanizovani, jer se programiranjem emocija otuđuju od svoje ljudskosti. Primeri te otuđenosti jesu Rik i Iren Dekard. Pripovest počinje Dekardovim buđenjem uz električni trzaj, poput mašine. Takav prizor oživljava uspo-

12 Imajući u vidu da je roman Sanjaju li androidi električne ovce? objavljen 1968. godine, u jeku borbe afroamerikanaca u SAD, nekadašnjih robova, za građanska i ljudska prava, takva paralela ne može biti slučajna. Poput crnih robova u periodu pre Američkog građanskog rata, koji su bežali od svojih gospodara tražeći slobodu na severu SAD-a gde su ih nemilosrdno lovili lovci na robove, tako $i$ androidi beže i katkad ubijaju svoje gospodare tražeći slobodu i bolji život na Zemlji, gde ih progone lovci na glave poput Dekarda. Na taj način, tzv. Drugi se dehumanizuju i smatraju inferiornim, manje vrednim bićima.

13 Dekard se stidi svoje električne ovce i skuplja novac da kupi pravu životinju. 
mene na filmske verzije buđenja Frankenštajnovog stvorenja: „Tvorac raspoloženja Proplanak postavljen pokraj njegovog kreveta uputio je kroz njegovo telo rukovođen automatom za buđenje, jedan vedri talasić elektriciteta koji je probudio Rika Dekarda“" (Dik, 2007: 7). Efekat užasa buđenja Frankenštajnovog stvorenja fildikovski je gotovo eliminisan time što je elektrošok predstavljen kao „vedri talasić elektriciteta“ (Dik, 2007: 7). Pridev „vedri“ u prethodnom navodu ukazuje na to da volja za životom u toj otuđenoj realnosti potiče od aparata, ne iz ljudske duše. Štaviše, stvorenje koje se podiglo iz kreveta obučeno je u „šarenu pidžamu“ (Dik, 2007: 7). Prizor na prvi pogled deluje komično. Međutim, upravo je ta komičnost put povratka pomenutog efekta užasa. Predstavlja način na koji se tehnologija i njena neodgovorna upotreba neprimetno uvukla u sve pore ljudskog društva. Načinila je čoveka zavisnim od sebe, oduzevši mu slobodu kroz potrošačku simulaciju života. Poput automata, Dekard se budi na pritisak dugmeta, doživljavajući to kao normalno, i sa suprugom razmatra koje bi raspoloženje mogli zajedno da programiraju. Takve okolnosti ističu njihovu mehanizovanost $i$ otuđenje. Bez pomoći mašine ne mogu ni emocije da podele. Dehumanizovanost uključuje i „zdravu“ dozu muškog šovinizma. Za svoju suprugu, Dekard bira program 594, „zadovoljno priznavanje da je muževljeva mudrost po svim pitanjima superiorna" (Dik, 2007: 10). Za sebe bira „kreativan i svež pristup svome poslu“ (Dik, 2007: 10). Po sopstvenom priznanju, to mu i nije potrebno, jer „i bez artificijelne stimulacije mozga Proplankom njegov pristup poslu bio je već po navici i po urođenoj sklonosti, kreativan i svež“ (Dik, 2007: 11). Dekard je gotovo tipski predstavljen kao toliko dehumanizovano biće da ga ni programiranje emocija ne može napraviti većim automatom nego što jeste. Utisak je poduprt i načinom na koji doručkuje, brzopotezno, kao i činjenicom da razgovor sa suprugom doživljava kao gubljenje vremena. Posao mu je toliko važan da ga ni rizik od genetske mutacije ne može naterati da emigrira. Dok razmišlja o državnoj paroli: „IZBOR JE VAŠ: SVEMIRSKA EMIGRACIJA ILI ZEMALJSKA DEGENERACIJA“ (Dik, 2007: 12), to postaje očigledno: „Živa istina [...]. Ali ja ne mogu zbog svog radnog mesta“ (Dik, 2007: 12). Razlog je jednostavan, novac. Utrošiće ga u skladu sa potrošačkom filozofijom kapitalističkog društva na statusne simbole koji su simulacija prave sreće i zadovoljstva. Električnu ovcu želi da zameni pravom životinjom kako bi podigao svoj status u društvu. Jedini način da do potrebnog novca dođe jeste odstrel odbeglih androida. Sebe ne doživljava kao ubicu. To je jedini način da mirne savesti nastavi da se bavi svojim poslom. Na Ireninu provokaciju da nije policajac, već „ubica koga su panduri unajmili“ (Dik, 2007: 7), uvređeno odgovara: „U životu nisam ubio ni jedno ljudsko biće“ (Dik, 2007: 7). Uveren u slične tvrdnje mogao je biti $i$ robovlasnik na jugu SAD pre građanskog rata, kada bi preteranim radom $u$ smrt oterao crnog roba, doživljavajući ga kao svojinu, nižu vrstu, domaću životinju kadru da govori, ali ne i ljudsko biće. Za takav primer mogli bi uzeti i nacističkog oficira koji bi dane provodio gušeći Jevreje u gasnim komorama, a zatim se vratio porodici uveren da nije učinio ništa loše ${ }^{14}$. To su primeri androidizacije ljudi. Na po-

14 Ukoliko čitalac želi bliže da se upozna sa Dikovim viđenjem nacističkog mentaliteta, može pročitati njegov roman Čovek u visokom dvorcu (1962). Fikcionalni svet tog romana počiva na alternativnoistorijskoj premisi da su sile osovine na čelu sa nacističkom Nemačkom odnele pobedu u Drugom svetskom ratu. 
četku romana, Dekard je simbol svega što se može desiti kada se ljudi otuđe, kada empatija postane selektivna i samo jedan od načina da se podigne status u društvu. Kroz Dekardov lik, Dik kritikuje moderni svet korporativnog kapitalizma prisutan ne samo danas, već i u vreme pisanja romana, koji ljude u bezglavoj trci za novcem čini bezosećajnim automatima. Sve što će se Dekardu dogoditi doprineće tome da postane drugačiji čovek. Na posletku, potreba za empat-kutijom kako bi osetio Mercerove muke nestaje: ,'Ja sam Vilbur Mercer; trajno sam se sjedinio s njim. Sad ne mogu da se razjedinim'. / [...] 'Ja više nisam službenik policije'“ (Dik, 2007: 189). Više mu nije potrebna simulacija empatije koju mu je pružala empat-kutija. Nije mu potrebno pomagalo da bi osećao. Otišao je u pravu pustinju, penjao se uz pravo brdo, udarale su ga prave kamenice, iz pravih posekotina na licu tekla je prava krv. Više nije empatisao sa simulacijom Mercerovih muka, doživljavao je sopstvene. Simulacija mu više neće biti potrebna, jer doživljava autentična osećanja: „Ko me gađao kamenom, zapita se. Niko. Ali zašto me to muči? To sam trpeo i pre, u sjedinjavanjima. Dok sam upotrebljavao svoju empatijsku kutiju, kao i svaki drugi. Ničeg tu novog nema. Ali ima, shvatio je. Jer ovoga puta, pomisli on, to sam uradio sam“ (Dik, 2007: 187-188, kurziv M. Š.). Postao je jedan od retkih koji je eliminisao potrebu za mehaničkim posrednikom da bi stupio u kontakt sa svojim emocijama. Simbolično, postao je sopstveni Mercer: „Imao sam apsolutnu, totalnu, potpuno realnu iluziju da sam postao Mercer i da ljudi bacaju kamenice na mene. Ali nije bilo kao kad držite ručice empatijske kutije. Kad koristite empat-kutiju osećate da ste sa Mercerom. Razlika je bila u tome što nisam bio ni sa kim; bio sam sam“ (Dik, 2007: 189-190).

Dubina Dekardove promene vidljiva je u sceni koja prethodi njegovom odlasku u pustinju. Dekardova androidska ljubavnica, Rahela Rozen, bacila je pravu kozu koju je nedavno kupio sa krova. Umesto da bude užasnut kao što bi ranije bio, Dekard izražava razumevanje za Rahelin postupak i njen „androidski razlog“ (Dik, 2007: 183). Više nije opsednut potrebom da poseduje pravu životinju. Buđenje novog, a kraj starog Dekarda može se naslutiti u sledećim rečima: „Biće sve u redu sa mnom', reče on, a u sebi reče, ali ću i umreti. I jedno i drugo je tačno“ (Dik, 2007: 183). Stari Dekard uslovno rečeno umire kako bi novi mogao da se rodi iz pepela. Koliko se promenio očigledno je u sceni povratka kući. Povratak porodičnom gnezdu simbolično predstavlja i povratak sopstvenoj ljudskosti. Kada Iren otvori vrata njihovog stana, prizor koji nam Dik predstavlja kroz Irenine oči slika je izmenjenog čoveka: „Zaokrugljene od divljenja njegove su oči sijale, kao oči malog dečka; izgleda, pomisli ona, kao da se igrao i da je sad došlo vreme da napusti igru i dođe kući. Da se odmori, opere i priča o čudesima proteklog dana“" (Dik, 2007: 193).

Kroz celu pripovest Dekard je sumoran i napet, a sada mu prvi put oči sijaju. Oči su ogledalo ljudske duše. U njegovim se da naslutiti povratak svega što je u njima ranije nedostajalo, uključujući i želju da se vrati supruzi od koje se otuđio. Žaba krastača koju iz pustinje donosi pojačava utisak Dekarda kao novog Mercera. Prema Isidorovim sećanjima, Mercer je zbog izumiranja te životinje naročito žalio (Dik, 2007: 24). Čak i kada se, u fildikovskom obrtu, ispostavi da je žaba električna, to Dekarda ne rastužuje previše. U sebi je pronašao ono najbitnije. Pronašao je sebe. 
Iren Dekard prolazi sličan put. Za razliku od muža, ne budi se na dugme, nije pomirena sa besciljnim potrošačkim postojanjem: „[O]tvorila [je] svoje sive, nevesele oči, žmirnula, onda zastenjala i opet ih zatvorila“ (Dik, 2007: 7). Zatvara oči nadajući se da će ono što vidi nestati kao ružan san. Programira Tvorca raspoloženja za nevesele emocije. Ne može da podnese da „čuje“ tišinu praznih stanova koje su vlasnici napustili otišavši u emigraciju, a da je to ne dotiče. Ne želi da programiranjem veselih emocija beži od stvarnosti: „Ali onda sam shvatila kako je to nezdravo, osetiti odsustvo života, ne samo u ovoj zgradi nego svuda, a ne reagovati - kapiraš? Rekla bih da ne kapiraš“ (Dik, 2007: 9). Zbog beznadežne realnosti koja je u sve većoj meri, poput naše, odsustvo života, Iren na suprugova nastojanja da je nagovori da „naruči“ raspoloženje može samo sumorno da kaže: „hoću prosto-naprosto da sedim ovde i buljim u patos“ (Dik, 2007: 10). Ne vidi ništa čemu bi se mogla radovati, a da to nije simulacija koja se konzumira kako bi se nadomestio nedostatak autentične radosti. Ipak, nada joj se vraća sa muževljevim povratkom kući. Pre Dekardovog povratka, osećajući „kako se kosti u njoj skupljaju od starosti“ (Dik, 2007: 193), Iren je na iskušenju da „naruči“ raspoloženje. Od toga odustaje, jer joj je za povratak smisla potreban njen muž i malo šta drugo. Kada bi imala iskren i neotuđen odnos sa mužem, psihološka pomagala joj ne bi bila potrebna: „[S]ad nije potrebno da naručujem raspoloženje; već ga imam - ovo je Rik. Potrčala je do vrata i širom ih otvorila“ (Dik, 2007: 193). Rikovim povratkom kući ponovo imaju jedno drugo u iskrenom ljudskom odnosu. Njemu više nije potrebno da na Tvorcu uključi „Odavno zasluženi mir“ (Dik, 2007: 196) kako bi spavao mirnim snom, a Iren može konačno da popije „šolju vruće crne kafe“ (Dik, 2007: 197), opušteno i dostojno čoveka, ne brzopotezno i mehanički kao Rik svoj doručak na početku.

U događajima tog sudbonosnog dana u životu glavnog junaka, važna je uloga Rahele Rozen, androidke u vlasništvu Asocijacije Rozen. Ona se uvlači u Dekardov život, potom i krevet, ne bi li ga ubedila da odustane od svog zadatka. To radi iz korporativnih razloga: „Konstrukt, kao simulacija stvarnog, u direktnoj je vezi sa korporativnim i državnim aparatima, koji svoje ciljeve ostvaruju kontrolom, manipulacijom i kreiranjem privida“ (Jakovljević, 2015: 104). Težnjom da izbriše razlike između ljudi androida, Asocijacija Rozen „proizvodi simulacije i manipuliše neautentičnim, što joj omogućava da kontroliše stvarnost i održava svoju korporativnu i tržišnu moć“ (Jakovljević, 2015: 105). Kapital, naročito savremenog korporativnog tipa, ne radi za dobrobit društva. To je u najboljem slučaju privid. Radi za sopstvenu korist, jer on "nikad nije bio vezan [društvenim] ugovorom za to društvo u kome vlada“" (Bodrijar, 1991: 19). Kako Rahelu, tako i druge androide, Dekard sve više doživljava kao žive. U njegovim očima, Rahela je „prepuna veselja i sasvim sigurno isto toliko ljudskog izgleda kao i bilo koja od devojaka koje je Rik dosad upoznao" (Dik, 2007: 159). Uprkos tome, Dekard ne želi da bude oruđe u bilo čijim rukama. Želi da se otrgne iz mehaničkog mrtvila koje dominira njegovim postojanjem. Ne želi da se poput androida miri sa sudbinom: „[M]račna vatra je jenjavala; životna sila je isticala, curila iz nje; toliko je to puta gledao kod drugih androida. Klasična rezignacija. Mehaničko, intelektualno prihvatanje onoga što istinski organizam [...] nikad ne bi 
mogao pomireno prihvatiti“ (Dik, 2007: 162). Trenutak kada Dekard ubija Pris Straton, Rahelinu kopiju, bodrijarovsku simulaciju simulacije, prema kojoj je počeo da razvija osećanja, nosi svoju simboliku. Ubijajući nju, Rik okreće leđa svemu što ga je sprečavalo da pronađe sebe: „Stajao je sam u praznom hodniku; [...] Rahela - tačnije Pris Straton - sad je bila raskomadana; na taj način nije preostalo ništa, ništa sem Rika samog“. (Dik, 2007: 179)

Isidor je lik koji gotovo da ne pravi razliku između ljudi i androida. Budući da spada u kategoriju posebnih ${ }^{15}$, on je i sâm u očima drugih manje vredan. Posebni jeste termin za ljude čiji su geni oštećeni radioaktivnom prašinom. Kao što androidima nije dozvoljen dolazak na Zemlju, posebnima nije dozvoljeno da emigriraju kako ne bi uprljali čistoću ljudske vrste:

'A na Zemlji, gospođo Klugman, u starim danima, da li ste se brinuli i zbog mogućnosti da vas klasifikuju, a-hm, kao nepodobnu?' 'A, da, moj muž i ja smo se takoreći na smrt brinuli zbog toga. Naravno, čim smo emigrirali, ta briga je nestala, srećom zauvek.' / U sebi je Džon Isidor mislio ogorčeno: A i za mene je ta briga nestala, iako nisam morao da emigriram. (Dik, 2007: 20)

Izopštenom iz ljudskog društva, nije mu teško da se identifikuje sa problemima androida. Njegova prostodušnost i potreba za emocionalnom bliskošću omogućavaju mu da ne doživljava androide kao nežive stvari. Tome pomaže njegovo doslovno verovanje u postulate Mercerizma, koje doživljava kao svetost života u ma kom obliku. Važna je i činjenica da ga Pris Straton fizički privlači, iako ona o njemu govori hladno i sa nipodaštavanjem. Ne ponašaju se svi androidi prema njemu na isti način, što pokazuje da poseduju ceo spektar ljudskih osećanja i ponašanja, od hladnoće i bezosećajnosti do razumevanja: „Ovaj pilećemozgovac', reče Pris, 'me simpatiše.' / 'Nemoj ga tako zvati, Pris', reče Irmgard; pogledala je Isidora saosećajno. 'Pomisli kako bi on mogao zvati tebe'“ (Dik, 2007: 131). Za razliku od Isidora, Dekard potiskuje empatiju uveravajući sebe u sveprisutnu mantru da su androidi nežive stvari. To mu omogućava da sebe ne doživljava kao ubicu:

Empatijom će živo biće sklono skupljanju u stada, čovek na primer, steći uvećanu sposobnost opstanka; ali sovu, ili kobru, empatija će uništiti. Iz čega jasno proističe da je humanoidni robot usamljena grabljivica. Riku je bilo prijatno da o njima razmišlja na takav način; onda je lakše podnosio ono za šta je bio plaćen da čini. (Dik, 2007: 30-31)

Kako radnja odmiče, Dekard počinje da sumnja u svoja uverenja, naročito nakon što Reš ubije androida Lubu Luft, opersku pevačicu. Posmatrajući Lubino telo oko koga se okupila svetina, Dekard shvata apsurdnost situacije u kojoj se nalazi: „Ne kapiram: kako je moguće da takav talenat bude nepoželjan našem društvu? Ali 
nije nepoželjan njen talenat, reče on sebi; samo je bila nepoželjna ona sama“ (Dik, 2007: 114). Njegovo razočarenje u sve što je verovao produbljuje se kada testira Reša. Ispostavlja se da je on čovek, iako je bezosećajni ubica bez empatije ni prema čemu sem životinjama. Testira i sebe, otkrivši da se u njemu razvio osećaj empatije prema nekim androidima. Razočaran je što se neko poput Reša može smatrati čovekom: „Znači, nisam bio u pravu. Nema ničeg neprirodnog i neljudskog u reakcijama Fila Reša; onaj čudan sam ja“ (Dik, 2007: 118). Pomenute reči imaju posebnu težinu u svetlu razmišljanja autora, Filipa K. Dika:

U univerzumu postoje okrutne hladne stvari koje sam nazvao 'mašine'. Njihovo ponašanje me plaši, naročito kada imitiraju ljudsko ponašanje tako dobro da imam nelagodan osećaj da te stvari pokušavaju da se predstave kao ljudi, a to nisu. Zovem ih 'androidi', što je moj način korišćenja te reči. (Dick, 1976: 211)

Android nije samo mašina kao replika, tj. simulacija čoveka, već se androidom može nazvati i rođeno ljudsko biće: „Ljudsko biće bez odgovarajuće empatije ili osećanja jednako je androidu napravljenom tako da ih nema“ (Dick, 1976: 211). Takvi ljudi gube osnovne kvalitete ljudskosti ponašajući se mehanizovano, poput mašina. Primer takvog „androida“ jeste Reš. Gorka pilula spoznaje Dekardu još više zastaje u grlu nakon što mu Reš uz cinični osmeh kaže da je u pitanju samo seksualna privlačnosti prema „androidkama“: „Ne dopusti da te to deprimira; ozdravićeš. Sve što se dogodilo, jeste to da si radio stvari pogrešnim redom. Nemoj da je ubiješ niti da budeš prisutan kad je ubijaju - pa posle da osetiš fizičku privlačnost. Obrni redosled“ (Dik, 2007: 119, kurziv M. Š.). Sve što Dekard može da učini jeste da sa nevericom „zuri“ u Reša započinjući svojim rečima jedini logični zaključak Rešovog razmišljanja: „Prvo da pođem s njom u krevet...., koji Reš surovo, uz isti „tvrdi, grubi osmeh“, privodi kraju: „... a posle je ubij“ (Dik, 2007: 119). Racionalno, mehaničko rezonovanje, lišeno saosećanja. Počevši taj dan kao još jedan lovac na glave, u Dekardu rastu sumnje u njegov dotadašnji način života. Budi se iz tmurnog sna i stupa u kontakt sa svojom ljudskošću: „Ti si dobar lovac na odstrelnine, shvati Rik. Tvoj stav to dokazuje. Ali, jesam li ja dobar? Iznenada, po prvi put u svom životu, u to je posumnjao“ (Dik, 2007: 119).

Celokupna pripovest odvija se u jednom danu. Prva i poslednja scena jedna su drugoj odraz u ogledalu. U obe vidimo Dekarda i Iren. Ipak, ljudi koje vidimo u poslednjoj sceni, više nisu isti. Kao da su ponovo postali ljudi. Otvorile su im se oči i zaista vide ne samo jedno drugo, već i svet oko sebe. Iz njega više ne pokušavaju da pobegnu otuđujući se jedno od drugog ophrvani unutrašnjim beznađem. Postali su humanizovani. Taj dan u Dekardovom životu proces je buđenja i raspršivanja iluzija. Na kraju pripovesti više nije ono što je bio. Ne želi da bude neautentično, tj. lažno ljudske biće (jednako androidu), već da očuva novostečenu ljudskost iako je i dalje okružen simulacijama: 
Bombardovanje pseudostvarnostima veoma brzo počinje da stvara neautentične ljudi, lažne ljude - lažne kao i podaci koji ih pritiskaju sa svih strana. [...] Lažne stvarnosti stvoriće lažne ljude. Ili, lažni ljudi stvoriće lažne stvarnosti i onda ih prodati drugim ljudima, čime će ih na kraju pretvoriti u sopstvene falsifikate. Tako završimo s lažnim ljudima, koji izmišljaju lažne stvarnosti i onda ih prodaju drugim lažnim ljudima. To je samo jedna veoma velika verzija Diznilenda. (Dick, 1978: 263)

Uverenje da je empatija rezervisana samo za ljude i prema ljudima sve više postaje iluzija i samoobmana proistekla iz straha. Takav strah proističe ne iz toga što su androidi različiti od nas, već iz straha da smo mi, usled obmana koje nam kao istinu i stvarnost nameće potrošačko društvo, postali poput mašina. Androidi su naši dvojnici, odraz u ogledalu, neugodni podsetnik na ono sa čim ne želimo da se suočimo u nama samima. Kako u našoj, tako i realnosti romana, simulacijama i lažnim stvarnostima ne može se uteći: „Danas je stvarno postalo alibi modela u svetu kojim vlada princip simulacije“, dok je „stvarno na paradoksalan način postala naša prava utopija - ali utopija koja više ne spada u red mogućeg, ona o kojoj se još može samo sanjati kao o izgubljenoj stvari“ (Bodrijar, 1991: 123-124). O tome svedoči i činjenica da Iren, ponovo uranjajući u simulaciju postojanja fildikovskog potrošačkog društva, za veštačku krastaču, koju je Dekard u trenutku pustinjskog prosvetljenja pronašao, naručuje "pola kilograma veštačkih muva koje stvarno lete uokolo i zuje, molim“ (Dik, 2007: 197). Poput romana koji počinje naslovom, ujedno i pitanjem, Sanjaju li androidi električne ovce?, tako se isti, praveći pun krug od androidizacije, preko prosvetljenja, nazad u potencijalno ponovnu androidizaciju, završava Ireninim pitanjem „šta ta krastača 'jede' [...]“ (Dik, 2007: 196-197).

\section{Zaključak}

Ukoliko se za trenutak vratimo prethodno analiziranoj sceni, primetićemo sledeće. Kao što androidi kao simulacije ljudi simuliraju snevanje simulacija ovaca, tako i simulacija krastače simulira da jede simulaciju muva koje simuliraju kako lete. U društvu koje je Dik predstavio, ekstrapolirajući krajnje posledice potrošačkog društva istorijskog trenutka u kome je pisao, a u čijoj unapređenoj varijanti danas živimo, razlike između autentičnog i neautentičnog, tj. simulacije, postaju nerazlučive. Otpor postaje nemoguć, budući da simulacija gradi sopstvenu stvarnost potirući te razlike: „Ali to nije važno. I električne stvari imaju svoje živote. Makar i kukavne“ (Dik, 2007: 195). Jedino što pojedinac može uraditi jeste da u takvom okruženju pokuša da sačuva ljudskost, da mnogobrojne slojeve simulacija posmatra s podozrenjem ne bi li uspeo da dokuči autentičnu istinu koja konstantno izmiče. To je jedini način da izbegne sopstvenu androidizaciju. U tome leži psihološka spoznaja do koje se, kroz formu (simulaciju?) detektivskog romana, stiže u ovom naučnofantastičnom delu. U tome i leži značaj Doleželovih i Suvinovih teorijskih postavki primenjenih na tumačenje ovog Dikovog romana. To se pokazuje tačnim utoliko što oba teoretičara insistiraju na saznajnoj funkciji, tj. spoznaji sveta koji nas okru- 
žuje, kao osnovnoj svrsi postojanja kniževnog dela, bilo ono naučnofantastično ili ne. Takva spoznaja ne može biti ograničena isključivo na čitaoca. Do nje dolaze i akteri pripovesti. Poznato nam eskapističko razrešenje, tipično za detektivsku književnost, biva iznevereno i zamenjeno psihološkim rastom. Takva spoznaja korenito menja doživljaj sveta koji su akteri do tog trenutka imali. Efekat koji Dik uspeva da postigne koristeći motiv takvog psihološkog putovanja, tj. potrage fikcionalnih likova, suprotstavljen je uobičajenom eskapističkom efektu koji nam donosi rasplet klasičnog detektivskog romana. Rasplet više ne donosi razrešenje koje dovodi do opuštanja napetosti zadovoljenjem čitaočevog apstraktnog shvatanja pravde i pravičnosti. Takva očekivanja bivaju podrivena i dovedena u pitanje. Kako čitalac, tako i akteri pripovesti ne bivaju izmireni sa predstavom koju imaju o svojoj realnosti. Naprotiv, rasplet vodi sve većem podozrenju prema onome što vide. Svrha spoznaje do koje dolaze akteri i čitaoci Dikove pripovesti nije udaljavanje od stvarnosti putem prilagođavanja slici sveta koju su s početka imali. Naprotiv, svrha takve spoznaje jeste ponovni osvrt na negativne pojave u stvarnosti koja ih okružuje i razaranje sopstvenih zabluda.

\section{Literatura}

Bodrijar, Ž. (1991). Simulakrumi i simulacije (F. Filipović, prev.). Novi Sad: Svetovi.

Gavrilović, Lj. (2010). O robotima i ljudima ili: Imaju li roboti dušu?. U B. Žikić (ur.), Naš svet, drugi svetovi. Antropologija, naučna fantastika i kulturni identiteti (str. 81-109). Beograd: Filozofski fakultet.

Gavrilović, Lj. (2011). Antropologija izmišljenih svetova. U Lj. Gavrilović (ur.), Svi naši svetovi. O antropologiji, naučnoj fantastici ifantaziji (str. 7-20). Beograd: Etnografski institit SANU.

Grgić, L. (2009). Šta ako androidi zaista sanjaju električne ovce?. Čemu, časopis studenata filozofije, 16/17, 69-81.

Dick, P. K. (1976) [1995]. Man, Android and Machine. In L. Sutin (Ed.), The Shifting Realities of Philip K. Dick: Selected Literary and Philosophical Writings (pp. 211232). New York: Vintage/Random House.

Dick, P. K. (1978) [1995]. "How to Build a Universe That Doesn't Fall Apart Two Days Later". In L. Sutin (Ed.), The Shifting Realities of Philip K. Dick: Selected Literary and Philosophical Writings (pp. 259-280). New York: Vintage/Random House.

Dik, F. K. (2007). Sanjaju li androidi električne ovce? (A. B. Nedeljković, prev.). Beograd: Algoritam.

Doležel, L. (2008). Heterokosmika. Beograd: Službeni glasnik.

Jakovljević, M. (2011). Alternativne stvarnosti Filipa K. Dika. Zbornik za jezike i književnosti Filozofskog fakulteta u Novom Sadu, 1(1), 229-238. Novi Sad: Filozofski fakultet.

Jakovljević, M. (2015). Alternativne stvarnosti Filipa K Dika. Kosovska Mitrovica/Beograd: Filozofski fakultet u Prištini sa privremenim sedištem u Kosovskoj Mitrovici/Makart. Kayman, M. (2003). The Short Story from Poe to Chesterton. In M. Priestman (Ed.), The Cambridge Companion to Crime Fiction (pp. 41-58). Cambridge: Cambridge University Press. 
Knight, S. (2003). The golden age. In M. Priestman (Ed.), The Cambridge Companion to Crime Fiction (pp. 77-94). Cambridge: Cambridge University Press.

Misselhorn, C. (2009). Empathy and Dyspathy with Androids: Philosophical, Fictional and (Neuro-)Psychological Perspectives. Konturen, 2(1), 101-123.

Panek, L. (2003). Post-war American Police Fiction. In M. Priestman (Ed.), The Cambridge Companion to Crime Fiction (pp. 155-171). Cambridge: Cambridge University Press. Priestman, M. (2003a). Introduction: crime fiction and detective fiction. In M. Priestman (Ed.), The Cambridge Companion to Crime Fiction (pp. 1-6). Cambridge: Cambridge University Press.

Priestman, M. (2003b). Post-war British Crime Fiction. In M. Priestman (Ed.), The Cambridge Companion to Crime Fiction (pp. 173-189). Cambridge: Cambridge University Press.

Rowland, S. (2010). The 'Classical' Model of the Golden Age. In C. J. Rzepka and L. Horsley (Ed.), A Companion to Crime Fiction (pp. 117-127). Chichester: Wiley-Blackwell.

Suvin, D. (2009). Naučna fantastika, spoznaja, sloboda. Beograd: SlovoSlavia.

Šarkanj, D. (2017). Suvremeni kriminalistički roman na primjerima Gorana Tribusona, Pavla Pavličića i Milorada Stojevića (neobjavljeni magistarski rad). Filozofski fakultet, Pula.

Tomić, U. (2013). Britanski kriminalistički roman - ključni aspekti razvoja (neobjavljena doktorska disertacija). Filološki fakultet, Beograd.

\section{Mirko Ž. Šešlak}

\section{Summary}

\section{DO ANDROIDS DREAM OF ELECTRIC SHEEP? AS A SIMULATION OF THE DETECTIVE NOVEL}

Examining the novel Do androids dream of electric sheep? from the point of view of the possible worlds theory according to Lubomir Doležel and Darko Suvin's theoretical work on science fiction, this paper analyzes how the writer adapts the plot characteristics of detective literature, the epistemic mystery story, to the inner quest of the protagonist of a science fiction novel. In contrast to the two-dimensional characters of the classic detective story, Dick's characters are multi-layered and their motivations are not easy to grasp. In this way, Dick denies the reader the classic escapist resolution of detective literature, which aims to release tension and provide the reader with a break from reality. Dick uses the elements of the classic plot of detective literature for purposes contrary to those of the classic detective story.

\section{Key words:}

detective literature, science fiction, Philip K. Dick, Darko Suvin, androids, androidization 